\title{
Informational features of WhatsApp in everyday life in Madrid: an exploratory study
}

\author{
Juan-Antonio Martínez-Comeche \\ University Complutense \\ Ian Ruthven \\ University of Strathclyde
}

\begin{abstract}
Author Note
Juan-Antonio Martínez-Comeche, Department of Library and Information Sciences, Faculty of Library and Information Sciences, University Complutense, C/ Santísima Trinidad 37, 28010 Madrid, Spain, Tel: +34 913946721, Fax: +34 913946689, Email: juaamart@ucm.es; Ian Ruthven, Department of Computer and Information Sciences, University of Strathclyde, , Glasgow G1 IXH, United Kingdom, Tel: +44 (0)1415484527, Fax: +44 (0) 1413304045, E-mail: ian.ruthven@strath.ac.uk

Correspondence and proofs concerning this article should be addressed to JuanAntonio Martínez-Comeche, Department of Library and Information Sciences, University Complutense, C/ Santísima Trinidad 37, 28010 Madrid, Spain, E-mail: juaamart@ucm.es
\end{abstract}




\section{Introduction}

Although many people do not have a smartphone or do not participate in social media at all, many other people in their daily life have access through their phones to multiple applications that allow them to communicate, access information, interact socially and entertain themselves, which are the main motivations for Internet use identified in the literature [1]. Social networking sites (SNS), perceived as having the primary purpose of developing and maintaining social relationships, have become the most popular online applications, constituting an important part of Internet activity [2]. At the same time, Mobile Instant Messaging (MIM) apps, among which WhatsApp stands out, are conceived as personal communication forms that have modified interpersonal interaction beyond orality [3]. In this regard, the literature points out that they have altered personal communication habits and are growing unceasingly as the first form of communication for those who use it [4].

However, several factors influence the way these applications are used, significantly altering their purpose and reach. It has been evidenced that social networking sites can also contribute to meeting the information needs of their users [5], or that MIM applications can aid in the maintenance and development of social relationships [6]. On the other hand, cultural and social differences entail changes in user behavior [7], therefore, SNS and MIM users have varied motives to adopt these applications and they use them for different purposes and reach, and this variation in use depends on many factors including cultural ones [8]. Even differences in users' personalities can influence their use of technology: while some choose to blend private and professional in the same SNS or MIM, for example, others would rather use separate applications, each having its specific purpose [9].

In summary, the considerable divergences in communicative purposes and differences that have been observed and that depend on the activities carried out by the user, their gender and age, among other factors, justifies this study of the characteristics of the information exchanged in everyday life by WhatsApp users in Madrid considering gender and age variation.

In the next section we review the literature and pose the research question. Afterwards, we describe the research methodology and present the results of the analysis. The section following then tackles the discussion; and lastly, we include the limitations and conclusion of the study. 


\section{Literature Review}

Although WhatsApp is currently considered the main messaging app for smartphones -by the end of 2017, it had up to 1.5 billion active monthly users [10]- its study had usually been restricted to the analysis of the communicative roles it played among young people from Asia [11] and America [12], or to the study of its informative use in certain fields of knowledge, such as Health [13,14], Education [15,16], and to a lesser extent in relation to Documentation [17] and Journalism [18,19]. Regarding the types of groups analyzed, there are a large number of student groups [20-22] and groups of professional teams [23,24], but friend and family groups $[3,25]$ have rarely been studied.

\subsection{Informational features in SNSs and MIMs}

Despite the growing informative importance of SNSs and MIMs, there do not appear to be any studies in the literature on WhatsApp from the perspective of daily information needs of any kind (of a professional, familial or social kind) that this application helps to meet throughout the daily life of users whose ages range between 13 and 60 years old. Therefore, the main purpose of this study is to explore which are the characteristics of the information exchanged daily through WhatsApp among users in Madrid, beyond the limited vision of SNSs or MIMs as platforms people can use to keep their acquaintances or close ones updated on mundane activities, such as what they had for breakfast, etc. [26]. We focus on users who live in Madrid in order to benefit from the experiences of those who live an area in which WhatsApp is widely used - WhatsApp is the first application by number of users in Spain, above Facebook [4].

The Uses and Gratifications Theory (UGT) was initially applied to audience behavior in the use of mass media, and later expanded to the analysis of any kind of communication technologies [27]. UGT assumes every individual is an active participant in the selection and use of media that satisfies their needs and wants, and that they experience certain gratifications as consequence [28]. In line with this approach, we propose users select and use SNS, MIM or e-mail applications for specific communicative purposes that are different for each one of these tools and that users never act indiscriminately --they use every application for every purpose simultaneously [29]. 
In the literature various motives for the use of SNSs and MIMs have been described using UGT: seeking information, seeking entertainment, social interaction, reinforcement of personal identity and self-disclosure [30]. Usability and functionality [31], or emotional support and a sense of belonging [32], among others, have been included.

Previous research has pointed out that social interaction is not the only main reason that leads individuals to use SNSs and MIMs [33,34], users also share information $[35,36]$. However, when the analysis has a more informative perspective, it is not usual to delve much into the kind of information exchanged in SNSs and MIMs, and it is common to merely mention information sharing or content sharing as one of the characteristics of social media use $[34,37]$.

We know the information exchanged can vary depending on the social media platform being used [9]. In the case of MIMs, particularly, it is primarily information regarding everyday life [38]. While managing the daily routine associated with family, friends, work and leisure, the kind of information exchanged in MIMs varies greatly based on the users and the nature of their daily activities. For example, gender can affect the kind of information exchanged in MIM group chats. One study identified differences in the topics addressed in group chats formed by Jordanian women and group chats formed by Jordanian men [39]. Studies have also found that the older the user, the less they participate in WhatsApp group chats [40]. Even the personality of the user can modulate the importance of certain WhatsApp group chats [3]. In relation to cultural factors, one study analyzed how the beliefs and perspective of Ghanaians can affect the information they share in SNSs and MIMs [41], while another found that social factors can have a significant impact on the way MIMs are used in China [42]. Regarding the importance of daily activity, another study found the information searched and exchanged in a Catholic clergy group chat in Northern Nigeria is related to sermons, homilies or Church teachings [43]. Such information is very different from the kind Hong Kong young urbanites [6] or Syrian refugees in Vienna share, as they are more interested in geographical orientation or language learning and translation [44].

\section{Research Questions}

The reviewed literature did not provide sufficient support to develop hypotheses about informational features of WhatsApp in everyday life in Madrid. Therefore, we designed an exploratory study by focusing on the following research question: 
RQ. What are the characteristics of the information exchanged in everyday life in WhatsApp when considering both genders and a wide range of ages of citizens of Madrid?

\section{Method}

We employed a qualitative method for the study of informational features of WhatsApp in everyday life of citizens of Madrid with a wide range of ages. The analysis of the informational features was carried out by means of semi-structured interviews.

In similar studies the samples usually range from 17 people, when solely conducting interviews [45], to 40 people, when various experiments are added to the questionnaires [46]. In our case, we have selected a convenience sample of 30 people, 14 men and 16 women ranging in ages from 13 to 58 years old. To constitute the sample we have used the snowball sampling technique, a suitable procedure for cases like this one, in which the target population is difficult or impossible to locate [47] and is integrated in social networks [48]. For the starting point of the sampling a teacher from a Secondary Education Institute in Madrid, who was in her fifties, was selected, because she was an active user of WhatsApp and part of numerous group chats -both in a professional and private context- in which she participated daily, excluding the group chats she only consulted or participated in sporadically. This ensured, on the one hand, the recruitment of enough subjects for the sample. On the other hand, since she maintained a close relationship with the members of her group chats, it also facilitated localizing and contacting other potential participants in the study. Moreover, since she was involved in active teaching projects and held a management position in her workplace, she allowed the addition of students between 13 and 18 years old as well as participants that approached the professional aspects of interest in the study. Among them, 30 people agreed to take part in the study, with the consent of their legal guardians in the case of minors. The sample distribution is summarized in Table 1.

Table I. Sample distribution 
Group chat

People in the group

Number of participants

Family unit

Broader family

Friends from

adolescence

Current friends

Professor-students

Professors
Parents and children

Siblings, their husbands,

5

spouses and children

Old friends

3

Recent friends

7

Students in a teaching project

9

3

The interviews were carried out in the Institute by one of the authors. The participants were asked about their everyday use of WhatsApp with particular focus on their use and frequency of the use of Internet and social media; the types of WhatsApp conversations in which participants engaged; the informational purpose in the use of WhatsApp; and personal and social aspects of the use of the application for the participant and their close circle. They were also asked to briefly describe an experience in which they were paying attention to WhatsApp, trying to select one event that was usual in their daily life, so that a sample of everyday issues resolved through WhatsApp could be collected. . Many users pointed out that they frequently deleted messages in order to save storage in their phones, which prevented us from using the analysis of the interviewees' WhatsApp messages in addition to the interviews. The interview and questionnaires took approximately 60 minutes. 
The interviews were recorded, transcribed and entered into NVivo for analysis by one of the authors. For the coding of the conversations and extraction of categories about WhatsApp grounded theory was used [49], because it allowed us to draw hypotheses about the thoughts of the participants from the systematic treatment of all the transcribed material. NVivo tools were employed to facilitate the analysis task, carried out in three stages: (a) an initial stage in which generic categories were assigned to the interview fragments in regards to any aspect pointed out by the interviewees, without applying preconceived categories; (b) a second stage in which, by the constant comparative method, the previously obtained categories were reviewed on several occasions, comparing all the fragments encoded under each of them, and compressing the categories as much as possible to summarize the aspects pointed out by the interviewees, always ensuring that they accurately represented what was expressed by them; (c) lastly, the most significant and frequent codes in relation to the object of study were selected.

\section{Results}

\subsection{Informational typology}

First we examine the informational typology of the messages exchanged in WhatsApp. Table 2 shows description and meaning of the identified categories.

Table 2. Informational typology of WhatsApp messages: Identified categories

\begin{tabular}{lll}
\hline Category & Description & Main goal \\
\hline $\begin{array}{l}\text { Trivial private } \\
\text { daily information }\end{array}$ & $\begin{array}{l}\text { Messages on daily } \\
\text { matters concerning } \\
\text { the user or his/her } \\
\text { contacts that do not } \\
\text { affect aspects considered } \\
\text { relevant by the user }\end{array}$ & $\begin{array}{l}\text { Exchange or seeking } \\
\text { of information in order } \\
\text { to solve everyday } \\
\text { problems or tasks related } \\
\text { to family, friends, work } \\
\text { or leisure }\end{array}$ \\
$\begin{array}{l}\text { Ludic, fun or } \\
\text { recreational } \\
\text { information }\end{array}$ & $\begin{array}{l}\text { Messages in a relaxed tone, } \\
\text { jokes or funny scenes, } \\
\text { about private or public issues }\end{array}$ & $\begin{array}{l}\text { Dissemination of } \\
\text { information on opinions, } \\
\text { criticism or praise, } \\
\text { personal or previously } \\
\text { elaborated by others, }\end{array}$
\end{tabular}


Personal affective information

Public daily information

Long-distance social relationships
Messages about thoughts, feelings or events considered relevant to the user that impact him/her emotionally

Messages about news or recent events of a public nature

Messages with acquaintances with whom the user have a far, distant or sporadic relationship highlighting funny aspects of the daily reality

Self-expression and seeking complicity, emotional support or advice

Dissemination of current information of general interest

Maintaining social relationships, showing interest in that contact and stay up-to-date on news about that person

Trivial private daily information is the most predominant and was frequently factual in nature: "Working relations are: let's meet up at this time, let's have lunch in this place. You're not talking about a report: I read your report, look at page three because this part... That's not how you use it [WhatsApp]" (S8, man, 53 years old, broader family group chat); "They are mainly plans, I mean, I usually talk to my friends daily about plans, things that happen in everyday life, news, events, mainly. And the same, but not with friends, with family, matters related to the family unit" (S13, man, 23 years old, group chat of current friends).

In our sample, WhatsApp is perceived as the tool dedicated to managing the exchange of the information needed to carry out trivial daily tasks. Table 3 shows some examples of this kind of information.

Table 3. Examples of trivial private daily information Information related to Example messages

Family

Friends
Who is picking up the kid from school today?, because I can't

Have you called the electrician?

Don't take the subway, line 6 is under construction

Where are we meeting up, then? 
Can we meet an hour later?, I need to do an errand

Have you thought of a birthday gift for him?

People with activities

or hobbies in common
Is there a math test tomorrow? (for classmates)

What time does the bus leave for Guadarrama? (for members of a trekking club)

Meeting in the conference room?

Who is on call today?

We have to cover for Pedro, he can't come to work today

The next frequent informational typology is ludic, fun or recreational information, sometimes related to current news: "There are friend group chats for funny stuff, while in family group chats you combine both things [...] Videos I receive and don't watch are basically all of them, unless someone tells me: have you seen this one?, it's really good. Then I watch it, but if no one does I don't waste my time with that" (S7, woman, 51 years old, broader family group chat).

Less frequent is personal affective information and finally public daily information, also frequently factual in nature. In relation to the first, the following fragment is representative:

"Interviewer: So you don't think [WhatsApp] is a place where you can express your feelings, or your religious or politic thoughts.

S1(woman, 19 years old, family unit group chat): I think you can, but I think it's much more interesting to share them later with someone, with a friend. To simply communicate them, I don't think it's necessary to go into those topics in WhatsApp. I, honestly, don't use it for that. But, well, people are very different"

Regarding public daily information, S8 comments: "Keeping up. Or, for example, if you have read or heard relevant information, you do send a text through WhatsApp: check El País, in section whatever..." (S8, man, 53 years old, broader family group chat). 
Related to the social aspect, the interviewees highlighted that WhatsApp is useful for maintaining long-distance social relationships. The application makes it possible to stay in touch with acquaintances that you do not have conversations with in person or on the phone. This aspect was pointed out by some of the interviewees:

"It's also for the people you don't see very often and every once in a while you think about them and say: I'm going to send them a WhatsApp because I'm not going to call them. To kind of keep in touch. For those social relationships you have sort of abandoned and every once in a while you go back to" (S28, woman, 25 years old, group chat of current friends).

Many uses of WhatsApp are, therefore casual and everyday, often based on hedonic purposes. This is mirrored in the pleasant experiences of using WhatsApp described in the interviews. When asked to describe a specific experience, the most frequent feeling at the beginning of the experience is neutrality, followed by joy and stress. In turn, the most frequent feelings at the end of the experiences are satisfaction, joy, relief, displeasure, and disappointment.

If we make the comparison between the initial and final emotions mentioned by the participants, in those cases in which the users describe themselves as neutral at the beginning of the experiences, the frequency of positive final feelings double the number of negative final feelings. In summary, the sessions during which we are paying attention to an issue in WhatsApp evoke more final positive feelings, although negative final emotions are also possible.

\subsection{Informational purposes}

There were three main informational purposes in the use of WhatsApp: 1) information exchange, followed by 2) information dissemination and lastly 3) keeping up with others' information in the group. Participant S3 commented on information exchange as follows: "Whenever I want information or others need some sort of information. For example, one of your children says: I'm going to so and so, stay connected in case I need help" (S3, woman, 52 years old, family unit group chat). 
Information dissemination is referred to in this fragment: "You're working in class [...] and suddenly it starts buzzing. You think: well, let's see what happens. Shift change, someone didn't come to work [...] You think: wait, I need to read it. What happens in the end? That you only read if your name is there" (S20, woman, 52 years old, group chat of friends from adolescence). In relation to keeping up with others' information, S30 says: "We can say that it is used [WhatsApp] to keep up with information about the group and with its plans" (S30, woman, 56 years old, group chat of current friends).

The participants also pointed out that text messaging is advantageous in comparison to oral communication when the message is not particularly complex or relevant, whenever it contains useful everyday information about daily activities. However, WhatsApp is considered insufficient in comparison to oral communication when the information is relevant, complex (that is, when it can lead to misunderstandings), extensive or urgent. Participant S27 explained it this way: "For nonsense or things that aren't very important, I do use WhatsApp, but for something a little more important, I do call. It's the closest thing to being face-to-face" (S27, man, 20 years old, group chat of current friends).

\subsection{Sense of freedom}

The interviews allowed us to extract other aspects of WhatsApp significant to the participants. One aspect highlighted by the interviewees is the lack of pressure in the use of WhatsApp, the sense of freedom it causes in general: "I think you feel free because it's you that is using it" (S4, woman, 46 years old, broader family group chat). This high level of freedom is reflected both in the possibility of belonging to group chats, and in the sense of freedom to intervene or participate or to take a personal stance on the topics addressed. Participant S11 explained it this way: "Always, in the group chats I'm in, if I don't want to be there I'm not. And if I am, maybe, and don't speak it's because I don't want to, and it doesn't pressure me in that sense" (S11, man, 22 years old, group chat of current friends). However users feel more limited when it comes to selecting words or expressions in their messages, although they do not feel pressured to use certain words: "Pressured to use certain words? Never pressured. I think it's normal to have to think about how to inform about things, either by text or in person. Even more so by text, because there can be many problems. But pressured, no. Keeping it in mind, always. I always consider how. I never feel pressured" (S13, man, 23 years old, group chat of current friends). 
The high level of freedom when expressing thoughts can have negative effects, such as harassment or bullying, a phenomenon that has come up in some of the interviews, and that users often attribute to not being in front of the other speaker in the communicative act. From the interviews we can infer that this aspect is related to the age of the user, being limited mainly to users between 13 and 15 years old: "[we have identified many cases of bullying] between kids. And young kids, on top of that. From first grade [of ESO], 13 or 14 years old, to third grade [of ESO, 14 or 15 years old]. Kids in fourth grade [of ESO, 15-16 years old] are different and they understand the magnitude. But the ones in first grade rely on the impunity [...] The last case has been this morning, on Monday. A girl that was threatened by two friends through WhatsApp. A girl is dating a boy, the boy liked someone else, they stop talking to her and on WhatsApp you can't imagine: I want to stab you..." (S26, man, 58 years old, professor group chat).

\section{Discussion}

The results obtained regarding the types of information exchanged through WhatsApp reflect that the categories resulting from the analysis were already present in previous studies on the use of social media. However, the sample in Madrid shows a different order of importance, with some unique characteristics. If the Ghanaian immigrants living in New Zealand exchange mainly public information about education, health, politics and sports through digital media [41], the corresponding category in our sample -public daily information, which is frequently factual in nature, then occupies a fourth spot in terms of importance. Moreover, while the most relevant public information among Ghanaian immigrants is related to health care and educational systems in New Zealand, and includes news about politics and sports to a lesser extent, in our study these last two aspects are the most significant, with no allusions to the educational and heath care aspects of the country. In regards to the most used digital channels, for this task the Ghanaian immigrants interviewed showed preference for e-mail, although social media or WhatsApp were used for exchanging information as well. In this aspect the differences with the population of Madrid are more prominent. While in our case only relevant or urgent information is communicated face-toface or by phone, Ghanaians prefer to share information of any kind by phone or face-to-face, because they do not trust online systems. Furthermore, while most Ghanaian immigrants, regardless of their age or gender, exchange this kind of information, in our case we can 
perceive a predominance of men in the group of people that include messages about politics and sports in WhatsApp.

The studies on the primary uses of social media highlight contacting friends and interacting with them as the one in first place, be it in Cyprus [31], Nigeria [50], the US or Korea [8]. The survey conducted among university students under 40 years old at a highly international university in Cyprus revealed the main reason for the use of WhatsApp and Facebook was keeping in touch with friends [31]. The undergraduates of a university in Nigeria agree that their favored applications are WhatsApp and Facebook, and that they are mainly used to maintain social contact with friends and relatives [50]. Undergraduate students of large universities in the US and Korea between 18 to 28 years old show that the primary reason for using social network sites is seeking friends [8]. Nevertheless, content analysis of personal mini-homepages in Cyworld, a Korean-based SNS, reflects that communication with family and friends is the least relevant reason for young Koreans in their late teens and early twenties to be present in this application, the main reason in this context being entertainment or passing time, among other factors [51].

For WhatsApp and Facebook specifically, maintaining social contact or keeping in touch with friends implies essentially getting the news about them [31,50], a category that in our study sample is the least frequent, as in [51], also restricting it to acquaintances or family members who live far away with whom the subjects maintain a sporadic relation. The new aspect in the Madrid sample is that it is not only young people who allude to social relations, but older adults as well, without any perceivable difference when it comes to gender. In our case, WhatsApp friend groups focus more on information exchange (where to meet up, with whom, when), even if it is trivial information.

In this regard, the greater importance of information in social media has been brought to attention [52], as supported by several studies [53,54]. In the case of MIMs, the dominant role of the exchange of practical information in these applications, in comparison to social media, had always been emphasized, as in the case of WeChat [22,55]. From the interviews conducted among ten young users of WeChat, the most popular MIM in China, Cui concludes that one of the types of conversations maintained in close relationships (family, friends, girlfriends/boyfriends) is the general information exchange, whose function is not to exchange important information, but to check that everything is as well as usual, that is, to confirm that the conversation partner's usual tasks are carried out normally [22]. A survey among two hundred WeChat users between 18 and 30 years old confirms that WeChat is 
considered a tool to receive and share useful and timely information, although the two primary motives for the use of WeChat are entertainment and social relationships [55].

In the particular case of WhatsApp, a previous study on its uses in Spain identified the coordination and planning of social activities with family members and friends as one the main uses [56]. In the survey conducted among users between 20 and 60 years old living in Spain about their motivations for using WhatsApp versus the traditional Short Message Service (SMS), many more people considered WhatsApp to be better than SMS for informal communications such as chatting, planning of social activities on the fly or sharing personal news and life events [56]. Our study supports this result including users between 13 and 18 years old, although it expands its scope to the exchange of any trivial private daily information, not just of a social kind. We should emphasize the fact that WhatsApp is considered by the participants of our sample as an assistance in quick communication of trivial information, which does not imply it is dispensable or useless. On the contrary, this type of information is extremely useful to successfully organize all the tasks and activities that fill a great part of our everyday life [57].

When analyzing individuals' information behavior in daily life contexts, one of the patterns that emerged was that the information communicated was frequently restricted to facts or data, despite the situations being very diverse [58]. The personal diaries and regular interviews of a participant in his early twenties about his information behavior in a daily life context show that, despite the diversity of daily situations found, an important characteristic of his information behavior is that in most occasions he tends to describe his information needs as facts or data. The authors of the study conclude that these daily life information seeking activities move away from formal sources like information systems and towards personal and electronic sources like the Web or e-mail [58], instead.The results obtained in our case fully reinforce this extreme when it comes to both private and public information, with no significant variation in regards to gender or age. This aspect, however, had not been reflected in the literature on SNSs or MIMs.

UGT emphasizes that people choose a traditional communication media (television, library) or a non-traditional media (SNS or MIM) depending on their needs, obtaining as a consequence diverse gratifications [28]. This conceptual framework has identified five social and psychological needs or motivations: cognitive (related to acquisition of information), affective (linked to emotional experiences), personal interaction (aimed at increasing credibility and confidence), social (connection with family, friends or acquaintances), and 
tension release (related to escape and diversion) [59]. With the exception of personal interaction, the other four main needs are reflected in the information categories in this study.

From this perspective, previous studies on MIMs point out that the main motivations and consequent gratifications for the use of these applications are entertainment, above socializing and information, whether it be WeChat [55] or WhatsApp [60], although at times this predominant use is limited to young people and not applied to adults [38]. Regarding WeChat, the analysis of psychological motivations reveals that entertainment is the most influential factor, followed by sociality and information [55]. These results are consistent with the results obtained for WhatsApp based on the Unified Theory of Acceptance and Use of Technology 2 (UTAUT2), that incorporates, among others, variables like hedonic motivation, subjective norm (related to socializing) and performance expectancy (the extent to which using a technology benefits consumer, obtaining information, for example). The study concludes that the most influencing variable in the use of WhatsApp is hedonic motivation, which indicates that people use WhatsApp motivated mainly by pleasure, entertainment and fun [60].

In our sample, however, ludic, fun or recreational information is second in order of importance, quite far from trivial private daily information, with no significant variation in regards to gender or age. It tends to be exchanged in a video or image format, and to a lesser extent, memes and texts are also used. In addition, it is important to note that sometimes it is information related to current affairs. Recently, for instance, the health emergency caused by Covid-19 has prompted the exchange in WhatsApp group chats of jokes and funny scenes about the public management of the pandemic, challenges for quarantine or scenes that highlight solidarity and affection values, as well as recognition for certain professions and positive attitudes. This aspect had already been identified among the uses of WhatsApp in Spain, although with much less importance than the one we obtained in our results. The interviews carried out by Church and Oliveira asked participants about the intent of WhatsApp messages, obtaining that this application is used primarily for chatting, quick catch-ups or coordination and planning, and finally silly things or jokes when linked to photos [56].

Lastly, albeit much less frequent, in the sample from Madrid we have spotted the exchange of personal affective information. This category includes messages about mood or feelings, personal news that have significantly affected the individual, or the search for emotional support. It had already been pointed out in relation to WeChat [22] and WhatsApp 
[61], and even in relation to the use of SMSs among Saudi students, applications that in the past shared many of the characteristics obtained now with MIMs [11]. The interviews with WeChat users showed that one type of interaction in this application was sympathetic companionship, defined by the author as a form of communication in which people seek psychological or emotional support from others [22], a category that is the same as the personal affective information in our sample. A survey of Bahraini women using WhatsApp daily, based on the Technology Acceptance Model (TAM), found that WhatsApp was used for sending not only comics and entertainment clips, but also important and rare news stories [61], close to the relevant events included in our definition of personal affective information. This result can be extended to the use of SMSs. Hundreds of text messages were collected from young Saudi university students, in order to discover the communicative functions of these texts. The analysis revealed that the main function was friendship maintenance. In this category, the users usually seek help and emotional support from their social circle [11]. These kinds of messages have the same characteristics as the personal affective information between users from Madrid, but in our sample they are not so frequent because users prefer to communicate relevant events face-to-face or by phone. Out of the different age groups, only late teens tended to include more of these kinds of messages.

We can conclude that it is necessary to use other cognitive attributes better suited for the specifically informative characteristics of this kind of applications. Both the informational typology and the informational purpose of these applications suggest the use of cognitive concepts widely used in the information seeking and retrieval field, such as uncertainty. In the middle of the 20th century, Shannon and Weaver developed a mathematical theory of communication that established a positive relationship between quantity of information and uncertainty, pointing out that the more a state of uncertainty is reversed by receiving a message, the more quantity of information has been provided by the message [62].

Uncertainty conceived as a degree of ignorance of the transmitted signal will later be adapted to several theories in the information seeking and retrieval field, now considering uncertainty as a cognitive state of the user caused by lack of knowledge, a state overcome when acquiring information. In the analysis of the Information Search Process (ISP) carried out by Kuhlthau trying to understand the user's perspective on the information seeking activity, she points out that in the initiation and exploration stages of the process, the appearance of uncertainty and confusion is common, concluding that the ISP may be articulated around the principle of uncertainty, conceived as a cognitive state that commonly causes affective 
symptoms of anxiety and lack of confidence in the early stages [63]. This state in the user causes the beginning of a search for useful information. Similarly, in Wilson's problem-solving model [64] information seeking is suggested to be a goal-directed process, with the solution of a problem as the goal. Throughout this process, the user has several information sources (people or information retrieval systems) to resolve his or her uncertainty [65]. For example, if a user wishes to reduce his or her uncertainty about the opening hour of the grocery store on holiday, he or she can obtain the information needed by consulting the company's website or asking the question in the family group chat. In consequence, the informative aspect of the Whatsapp messages suggests the relevance of the uncertainty analysis in this type of applications.

The analysis of the interviews considered in this study has also allowed us to discover a new concept in the cognitive factor that is worthy of more study. We are referring to the sense of freedom, or the corresponding lack of pressure, that users perceive when expressing their thoughts and sending them through WhatsApp. It is possible to approach this sense of freedom within the Everyday Life Information Seeking model (ELIS) developed by Savolainen [66]. This model is based on the concept of "way of life", defined by the author as "order of things", that is, the activities individuals choose to do in their daily lives and which preference they give to each of them depending on personal values and attitudes. According to this approach, sample individuals are highlighting the sense of freedom as one of the main values that in turn influence the way of facing their daily tasks or "mastery of life", and therefore, their behavior when it comes to solving daily problems, including the information seeking process. The selection of WhatsApp as an appropriate channel to solve non-relevant problems is motivated, among other factors, by the sense of freedom the use of this application provides.

In principle, the sense of freedom or the corresponding lack of pressure is a favorable factor to the use of the application. The cause of this sense of freedom can come down to the connection users establish between WhatsApp and their use in their close circles with high levels of familiarity, as opposed to a higher level of exposure in wider unknown social circles associated to the use of other social media networks.

\section{Limitations}


Considering only one application limits this study, since there are situations in everyday life in which users choose other applications to manage the information they need. For instance, users can choose Google Maps to find out where a specific place is and what means of transportation is the most suitable to get there, or they can download the EMT's (acronym in Spanish for Municipal Transport Company) applications to determine how long it will be until a bus arrives at a certain stop. It would be desirable to expand the study to cover the main applications used in everyday practice.

The study is limited to Madrid and WhatsApp. In a first expansion, these results should be compared to other MIMs and other cities in Spain and Europe. We have not contemplated every age group, either, and in the future it would be necessary to increase the size of the sample, also including people over 60 years old in the study, in order to generalize these findings.

\section{Conclusion}

The results obtained allow us to verify the essentially informative purpose users have when using WhatsApp in Madrid. On the other hand, users mainly exchange private and trivial everyday information, frequently factual, very useful to manage many of the tasks they normally face in an everyday life context. We can therefore conclude that this text messaging application is perceived by the users as a useful tool in the resolution of issues that arise during the day, as long as they are not considered mildly relevant personally or socially.

These characteristics suggest that WhatsApp, and text messaging applications in general, are applications that will allow us to approach and delve into the analysis of the informational habits of most of the population, as well as into the problem-solving methods that require information exchange, in the context of professional, private, and social spheres, when those problems arise in life. That will allow us to expand our knowledge about the use of information by human beings in a scarcely addressed area of our field.

\section{References}

[1] $\mathrm{Ko} \mathrm{H}, \mathrm{Cho} \mathrm{CH}$ and Roberts MS. Internet uses and gratifications: A structural equation model of interactive advertising. Journal of Advertising 2005; 34: 57-60. 
[2] Benevenuto $F$, Rodrigues $T$, Cha $M$, et al. Characterizing user behavior in online social networks. In: Feldmann A and Mathy $\mathrm{L}$, (eds.). Proceedings of the 9th ACM SIGCOMM conference on Internet measurement. Chicago, Illinois, USA: ACM, 2009, p. 49-62.

[3] Aharony $\mathrm{N}$ and Gazit T. The importance of the Whatsapp family group: an exploratory analysis. Aslib Journal of Information Management 2016; 68: 174-192.

[4] Fundación Telefónica. Sociedad Digital en España 2018. Barcelona: Penguin Random House Grupo Editorial, 2019.

[5] Sin S-CJ and Kim K-S. International students' everyday life information seeking: The informational value of social networking sites. Library \& Information Science Research 2013; 35: 107-116.

[6] Cho $\mathrm{V}$ and Hung $\mathrm{H}$. Sending mobile messages to different social ties in modern urban life. How do anxiety and time-shortage matter? Information Technology \& People 2015; 28: 544-569.

[7] Taylor RS. Information use environments. In: Dervin B and Voigt MJ (eds) Progress in Communication Sciences. Norwood, NJ: Ablex Publishing, 1991, pp.217-254.

[8] Kim Y, Sohn D and Choi SM. Cultural difference in motivations for using social network sites: A comparative study of American and Korean college students. Computers in Human Behavior 2011; 27: 365-372.

[9] McCay-Peet L and Quan-Haase A. A model of social media engagement: User profiles, gratifications, and experiences. In: O'Brien $\mathrm{H}$ and Cairns $\mathrm{P}$ (eds) Why engagement matters: Cross-disciplinary perspectives of user engagement in digital media. Cham, Switzerland: Springer, 2016, pp.199-216.

[10] Iqbal M. WhatsApp revenue and usage statistics (2020), businessofapps.com/data/whatsapp-statistics/ (2020, accessed 1 April 2020).

[11] Al Rousan R, Abdul Aziz N and Christopher A. Where are you? The communicative functions of Saudi students' text messaging. International Journal of English Linguistics 2014; 4: 23-33.

[12] Birnholtz J. Adopt, adapt, abandon: Understanding why some young adults start, and then stop, using instant messaging. Computers in Human Behavior 2010; 26: 1427-1433.

[13] Kamel Boulos MN, Giustini DM and Wheeler S. Instagram and WhatsApp in health and healthcare: An overview. Future Internet 2016; 8: 37.

[14] Mars M and Scott RE. WhatsApp in Clinical Practice: A Literature Review. In: Maeder AJ, Ho K, Marcelo A et al. (eds) Promise of New Technologies in an Age of New Health Challenges. 2016, pp.82-90.

[15] Trenkov L. Managing teacher-student interaction via WhatsApp platform. In: Chova LG, Martinez AL and Torres IC (eds) Edulearn14: 6th International Conference on Education and New Learning Technologies. 2014, pp.6596-6600.

[16] Bottentuit Junior JB, Albuquerque OCP and Coutinho CP. WhatsApp in Education: a Systematic Review of the Literature. Revista Educaonline 2016; 10: 67-87.

[17] Ansari MS and Tripathi A. Use of WhatsApp for Effective Delivery of Library and Information Services. Desidoc Journal of Library \& Information Technology 2017; 37: 360-365.

[18] Negreira-Rey MC, Lopez-Garcia X and Lozano-Aguiar L. Instant Messaging Networks as a New Channel to Spread the News: Use of WhatsApp and Telegram in the Spanish Online Media of Proximity. In: Rocha A, Correia AM, Adeli H, et al. (eds) Recent Advances in Information Systems and Technologies. 2017, pp.64-72.

[19] Silva FGFeS, Colussi J and Rocha PM. WhatsApp as a Tool for Participation on Spanish Radio: A Preliminary Study of the Program Las Mañanas on RNE. Journal of Radio and Audio Media 2018; 25: $77-$ 91.

[20] Hershkovitz A, Abu Elhija M and Zedan D. Whatsapp is the message: Out-of-class communication, student-teacher relationship, and classroom environment. J Inf Technol Educ-Res 2019; 18: 73-95.

[21] Fuentes Gutiérrez V, García Domingo M and Aranda López M. Groups of class; Groups of WhatsApp. Analysis of communicative dynamics among university students. Prisma Social 2017: 144-171.

[22] Cui D. Beyond "connected presence": Multimedia mobile instant messaging in close relationship management. Mobile Media \& Communication 2016; 4: 19-36.

[23] Crisan-Dabija RA and Mihaescu T. Creating a successful medical team using Whatsapp(TM). Eur Resp J 2018; 52: 2.

[24] Brewster CT and King ICC. WhatsApp: Improvement tool for surgical team communication. Journal of Plastic Reconstructive and Aesthetic Surgery 2017; 70: 705-706.

[25] Mwangi S. WhatsApp: The New Age Illusion of Friendships Among Kenyan Young Adults. In: Friedrichsen $M$ and Kamalipour Y (eds) Digital Transformation in Journalism and News Media: Media Business and Innovation. 2017, pp.263-270.

[26] Hough MG. Keeping it to ourselves: Technology, privacy, and the loss of reserve. Technology in Society 2009; 31: 406-413. 
[27] Lee CS and Ma L. News sharing in social media: The effect of gratifications and prior experience. Computers in Human Behavior 2012; 28: 331-339.

[28] Papacharissi Z. Uses and gratifications. In: Stacks DW and Salwen MB (eds) An integrated approach to communication theory and research. New York: Routledge, 2009, pp.137-152.

[29] Ku YC, Chu TH and Tseng CH. Gratifications for using CMC technologies: A comparison among SNS, IM, and e-mail. Computers in Human Behavior 2013; 29: 226-234.

[30] Omar AS, Rashid WEW and Majid AA. Motivations using social networking sites on quality work life. Procedia - Social and Behavioral Sciences 2014; 130: 524-531.

[31] Korhan $\mathrm{O}$ and Ersoy M. Usability and functionality factors of the social network site application users from the perspective of uses and gratification theory. Quality and Quantity 2016; 50: 1799-1816.

[32] Wellman B and Gulia M. Net surfers don't ride alone. In: Wellman B (ed) Networks in the global village. Boulder, CO: Westview, 1999, pp.72-86.

[33] Brandtzaeg PB and Heim J. Why people use social networking sites. In: Proceedings of the Third International Conference on Online Communities and Social Computing, OCSC 2009 (eds Ozok AA and Zaphiris P), 2009, pp.143-152. Berlin, Heidelberg: Springer.

[34] Quan-Haase A and Young AL. Uses and Gratifications of Social Media: A Comparison of Facebook and Instant Messaging. Bulletin of Science, Technology \& Society 2010; 30: 350-361.

[35] Coursaris CK, Sung J, Van Osch W, et al. Disentangling Twitter's adoption and use (dis)continuance: A theoretical and empirical amalgamation of uses and gratifications and diffusion of innovations. AlS Transactions on Human-Computer Interaction 2013; 5: 57-83.

[36] Gan C and Li H. Understanding the effects of gratifications on the continuance intention to use WeChat in China: A perspective on uses and gratifications. Computers in Human Behavior 2018; 78: 306-315.

[37] Joinson AN. 'Looking at', 'looking up' or 'keeping up with' people? Motives and uses of Facebook. In: Proceedings of the twenty-sixth Annual SIGCHI Conference on Human Factors in Computing Systems, 2008, pp.1027-1036. New York: Association for Computing Machinery Press.

[38] Matassi M, Boczkowski PJ and Mitchelstein E. Domesticating WhatsApp: Family, friends, work, and study in everyday communication. New Media and Society 2019; 21: 2183-2200.

[39] Al-Smadi AM. Gender and Age Patterns on WhatsApp Statuses as Used by Jordanians: A Sociolinguistic Perspective. International Journal of English Linguistics 2017; 7: 56-66.

[40] Gazit T and Aharony N. Factors explaining participation in WhatsApp groups: an exploratory study. Aslib Journal of Information Management 2018; 70: 390-413.

[41] Boamah E. Information culture of Ghanaian immigrants living in New Zealand. Global Knowledge, Memory and Communication 2018; 67: 585-606.

[42] Jiang G and Deng W. An empirical analysis of factors influencing the adoption of Mobile Instant Messaging in China. International Journal of Mobile Communications 2011; 9: 563-583.

[43] Dankasa J. Mapping the everyday life information needs of catholic clergy. Journal of Documentation 2016; 72: 549-568.

[44] Kaufmann K. Navigating a new life: Syrian refugees and their smartphones in Vienna. Information, Communication \& Society 2018; 21: 882-898.

[45] O'Brien HL and Toms EG. What is user engagement? A conceptual framework for defining user engagement with technology. Journal of the Association for Information Science and Technology 2008; 59 : 938-955.

[46] Jennett $C$, Cox AL, Cairns $P$, et al. Measuring and defining the experience of immersion in games. International Journal of Human-Computer Studies 2008; 66: 641-661.

[47] Babbie E. The practice of social research. Boston, MA: Cengage Learning, 2017.

[48] Cañadas-Osinski I and Sarabia-Sánchez FJ. Enfoque y métodos de muestreo. In: Sarabia-Sánchez FJ (coord.) Métodos de investigación social y de la empresa. Madrid: Pirámide, 2013, pp. 335-366.

[49] Charmaz K. Constructing grounded theory: A practical guide through qualitative analysis. London: SAGE, 2006.

[50] Nwokedi VC. Use of social networking sites amongst undergraduates: A case study of Department of Theater and Film Arts, Faculty of Arts, University of Jos, Jos, Nigeria. Library Philosophy and Practice (ejournal) 2019; 2236.

[51] Jung T, Youn $\mathrm{H}$ and McClung S. Motivations and self-presentation strategies on Korean-based 'Cyworld' weblog format personal homepages. CyberPsychology and Behavior 2007; 10: 24-31.

[52] Zong W, Yang J and Bao Z. Social network fatigue affecting continuance intention of social networking services. Data Technologies and Applications 2019; 53: 123-139.

[53] Lev-On A and Uziel V. Live, visual, social, and mobile: Media ecology in emergencies and ordinary times. Online Information Review 2018; 42: 545-558. 
[54] Orifah $\mathrm{MO}$, Ijeoma MC, Olajide BR, et al. Use of social media by agricultural undergraduate students in selected universities in Nigeria. Journal of Agricultural Extension 2017; 21: 120-128.

[55] Lien $\mathrm{CH}$ and Cao Y. Examining We Chat users' motivations, trust, attitudes, and positive word-of-mouth: Evidence from China. Computers in Human Behavior 2014; 41: 104-111.

[56] Church K and Oliveira R. What's up with WhatsApp? Comparing mobile instant messaging behaviors with traditional SMS. In: Proceedings of the 15yh International Conference on Human-Computer Interaction with mobile devices and services, Mobile HCl'13, pp.352-361.

[57] Seufert M, Schwind A, Hossfeld T, et al. Analysis of Group-Based Communication in WhatsApp. In: Mobile Networks and Management, Monami 2015 (eds Agüero R, Zinner T, Garcia-Lozano M, et al.), 2015, pp.225-238.

[58] Julien $\mathrm{H}$ and Michels D. Intra-individual information behaviour in daily life. Information Processing \& Management 2004; 40: 547-562.

[59] Salubi OG and Muchaonyerwa N. An empirical study of Internet usage pattern of undergraduate students in South Africa. Library Philosophy and Practice (e-journal) 2018; 2002.

[60] Fernández Robin C, McCoy S and Yáñez D. Whatsapp. In: Proceedings of the 9th International Conference on Social Computing and Social Media: Applications and Analytics, SCSM 2017 (ed Meiselwitz G), 2017, pp.82-90.

[61] Elareshi M and Ziani AK. Digital and interactive social media among middle east women: Empirical TAM study. Media Watch 2019; 10: 235-250.

[62] Shannon CE and Weaver W. The mathematical theory of communication. Urbana, IL: University of Illinois Press, 1949.

[63] Kuhlthau CC. Seeking meaning: A process approach to library and information services. Westport, CT: Libraries Unlimited, 2004.

[64] Wilson TD. Models in information behaviour research. Journal of Documentation 1999; 55: 249-270.

[65] Wilson TD, Ford N, Ellis D, et al. Information seeking and mediated searching. Part 2. Uncertainty and its correlates. Journal of the Association for Information Science and Technology 2002; 53: 704-715.

[66] Savolainen R. Everyday life information seeking: Approaching information seeking in the context of "way of life". Library and Information Science Research, 1995; 17: 259-294. 